\title{
Classy Delicates: A Case Study
}

Ram Subramanian, Montclair State University, USA

Ross A. Malaga, Montclair State University, USA

\begin{abstract}
Andy Steiner was checking the Internet for late night West Coast baseball game scores early on Saturday morning, August $3^{\text {rd }}$, 2007, when an email message popped up on his screen. It was a message from a prospective buyer for Classy Delicates, Steiner's online lingerie retailing business. Intrigued by the offer, Steiner contacted the prospective buyer who reiterated his intention and talked specific terms for the purchase. "Isn't this a coincidence," remarked Steiner to his wife, Julia. "We were just talking about the future of our business and here comes this new offer. This is the fourth offer we've had." "We should consider a sale of the business seriously," said Julia, "even though you were thinking of upgrading the site to improve traffic." "How much time do we have to examine the offers?" asked Julia to her husband. "The current buyer has made an offer to one other business and he told me that it's either the other business or us, and not both. I don't know if he is bluffing or not, but I think we have a week to decide for all four," answered Steiner.
\end{abstract}

Keywords: Internet retailing; business valuation; search engine optimization

\section{INTRODUCTION}

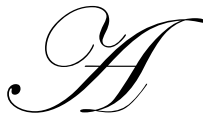

ndy Steiner was a business school professor at a university in New Jersey. Since 1996, he had specialized in teaching courses in the area of electronic commerce. When Steiner and his wife were in Maryland, Julia Steiner was unhappy at her job. The couple settled on the idea of starting a business of their own so that Julia could quit her current job. They explored various business possibilities, none of which panned out. While their search was going on, Steiner accepted a faculty job in New Jersey. Julia found a new job in New Jersey that she was happy in and pulled out of the owning a business idea. Steiner, however, continued his search for a business opportunity, except that now he focused on online businesses given his expertise in that area. He started an online store selling iPod accessories but quickly sold it, as he determined the market was too competitive. He came across an online lingerie store called Classy Delicates (www.ClassyDelicates.com). Steiner talked about his reasons for buying this business:

"Classy Delicates was an affiliate site directing users to online lingerie vendors and collecting a commission. I liked this site because lingerie vendors offered drop shipping to end users, which meant that I didn't have to carry inventory and the drop shipper took care of the details. Since I wanted to change it from an affiliate site to a retailing site, drop shipping was important to me. In addition, while the asking price was $\$ 75,000$, I was able to bargain it down to $\$ 30,000$ plus one and a half times the profits for the first three months, which turned out to be a measly $\$ 450$ because of all the changeover expenses! I essentially paid $\$ 30,450$ for a domain name and site traffic.

Steiner completed the purchase of Classy Delicates in August 2005. He immediately changed it from an affiliate site to a retail site. He contacted two leading intimate apparel vendors, Elegant Moments (Pennsylvania, USA) and DreamGirl (California, USA), who both agreed to drop ship products for Classy Delicates. Steiner redesigned the website that now featured large product images and a shopping cart system to handle customer purchases. He relaunched the site six weeks after purchasing the business.

Business was extremely slow in the first months of relaunch. Steiner reflected on this period:

"We were grossing around $\$ 200$ per month in the first couple of months. We moved up to around \$1,000 per month after six months and then averaged around \$3,000 per month toward the end of the first year of purchase. We were 
getting lost in the avalanche of websites that now existed on the web. In addition, Yahoo went through a major update in January and February of 2006. During an update, sites usually get shuffled around a lot. We effectively disappeared completely from Yahoo during this period. Since this was our major source of traffic to the site, and since February - because of Valentine's Day - is our biggest month for sales, this hurt us a lot.

To address the slow business problem, Steiner purchased pay-per-click (PPC) advertisements on Google. PPC ads appear on the top and right-hand side of the results page after a user types a query in Google (see Exhibit $1)$.

\section{EXHIBIT 1: Pay-Per-Click (PPC) Ads on Google}

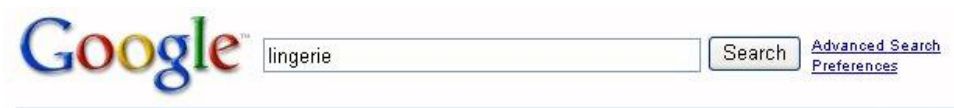

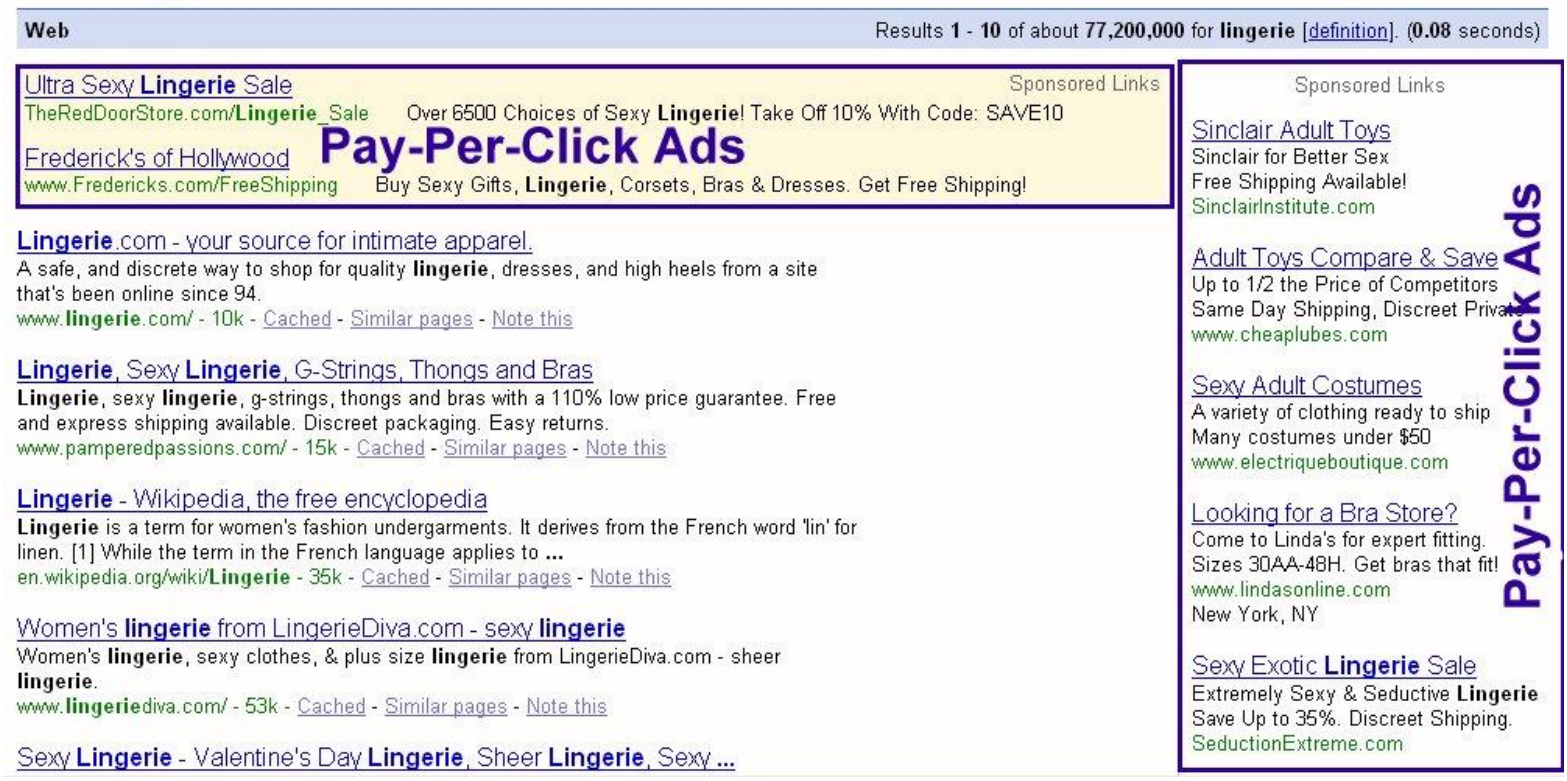

Merchants bid on words and phrases. When one of them was entered into Google, the ad would appear. The PPC campaign produced a negative return on investment and was soon discontinued.

Steiner then tried a second marketing approach. He used search engine optimization (SEO). SEO was a set of techniques aimed at having a site appear toward the top of the search engine results page (SERP) for a certain query. The main difference between SEO and PPC was that with PPC, the merchant pays for every click. With SEO, the clicks were free. In addition, Steiner found recent research (Sen 2005) that showed that users trusted the SEO (called organic) results and were more likely to purchase from them (Exhibit 2 describes SEO in greater detail and Exhibit 3 depicts meta tags used in organic search listings).

\section{EXHIBIT 2: Search Engine Optimization}

\section{How Search Engines Work}

A search engine is simply a database of web pages, a method for finding web pages and indexing them, and a way to search the database. Search engines rely on spiders - software that follows hyperlinks - to find new web pages to index and insure that pages, which have already been indexed, are kept up to date. 
Although more complex searches are possible, most web users conduct simple searches on a key word or key phrase. Search engines return the results of a search based on a number of factors. All of the major search engines consider the relevance of the search term to sites in its database when returning search results. So a search for the word "car" would return web pages that had something to do with automobiles. The exact algorithms used to determine relevance are constantly changed and often kept secret. For example, Google's algorithm considers over 60 factors to determine relevance ("Google's Patent", n.d.).

\section{SEO History and Current Situation}

The concept of optimizing a website, so that it appears toward the top of the results when somebody searches on a particular word or term, has existed since the mid 1990's. Back then, the search engine landscape was dominated by about 6-10 companies, including Alta Vista, Excite, Lycos, and Northern Lights. At that time, search engine optimization (SEO) largely consisted of keyword stuffing; that is, adding the search term numerous times to the website. A typical trick employed was repeating the search term hundreds of times using white letters on a white background. Thus the search engines would "see" the text, but a human user would not.

The search engine market and SEO had changed dramatically over the past few years. The major shift had been the rise and dominance of Google. Google currently handles more than half of all web searches (Burns 2007). The other major search engines used in the United States are Yahoo and MSN. Combined, these three search engines are responsible for over $91 \%$ of all searches (Burns 2007).

In addition, recent research indicates that most search engine users only click on sites that appeared on the first page of the search results - basically the top ten results. Very few users click beyond the third page of search results.

The dominance of the three major search engines (and Google in particular), combined with the research on user habits, means that for any particular search term, a site must appear in the top 30 spots on at least one of the search engines or it is effectively invisible. So, for a given term; for example, "lingerie", there are only 90 spots available overall. In addition, 30 of those spots (the top ten in each search engine) are highly coveted and the top ten spots in Google are extremely important.

\section{Practical Aspects of SEO}

SEO consists of three main processes - indexing, on-site optimization, and obtaining links.

\section{Indexing}

Indexing is the processes of attracting the search engine spiders to a site, with the goal of getting indexed (and hopefully ranked well) by the search engine quickly. All of the major search engines have a site submit form where a user can submit a site for consideration. However, most SEO experts advise against this approach. It appears that the major search engines prefer "discovering" a new site. The search engines "discover" a new site when the spiders find a link to that site from other sites. So the main approach to indexing involves getting links to a site from other sites that are frequently visited by the spiders.

A typical method for getting a site indexed is the so called "Blog-Ping" approach. This technique consists of setting up a Blog on a well known Blog site. Many SEO experts prefer Blogger for this since it is owned by Google and visited often by Google's spider. Once the Blog is set up, the SEO expert begins posting short articles with a link back to the site he wants indexed. The final step is to ping the Blog. Pinging is a service that tells Blog search engines and other sites that the Blog had been updated. By using the Blog-Ping approach, sites are usually indexed very quickly (in just a few days or less). 


\section{On-Site Optimization}

On-site optimization is the process of making changes to a website in order to improve its search engine rankings. Some of the main on-site factors used by the search engines in order to determine rank include title tag, meta description tag, H1 tag, bold text, and keyword density.

Meta tags are hypertext markup language (HTML) elements that describe a web page. They are not visible on the page, but are visible to the search engines. Two meta tags - title tag and description tag - are used by the search engines in two ways. First, they use the tags as one of many elements that are considered when determining search engine rankings. Second, many search engines display the title and description tags in the search listings (see Exhibit 3).

Steiner tested many different versions of the title and description tags. He noticed that small changes to the title tag made a big difference in Classy Delicates search engine ranking - particularly on Yahoo. By changing these tags Classy Delicates began to rank on the second page in Yahoo for the term "lingerie".

H1 tags are HTML elements that indicate the text is considered to be a level one header. Many search engines place importance on $\mathrm{H} 1$ headers and text that appears in bold on the web page. Steiner added H1 headers and bold text to the main page and each category page on the site. The headers and bold text on the main page seemed to improve the site's Yahoo ranking slightly. In addition, a number of the category pages, such as bustiers and corsets, began to rank well in Yahoo.

Keyword density is a measure of how often a certain word or phrase appears on a site. There is considerable debate among SEO practitioners as to the optimum level of keyword density. Most agree that if the keyword density is too high the search engines begin to penalize a site. However, since the search engines keep this level a secret, determining the best keyword density often requires a great deal of trial and error.

By using on-site optimization techniques, Steiner was able to achieve excellent search engine rankings for the terms "lingerie", "women's lingerie", and "sexy lingerie" in Yahoo. Classy Delicates was usually ranked on the first or second page for "lingerie". The site was usually ranked first or second in Yahoo for "women's lingerie" and "sexy lingerie".

\section{Link Building}

All of the major search engines consider back links in their ranking algorithms. A back link is a hyperlink from a site to the target site - in this case Classy Delicates. All of the major search engines also consider the relevance of the text used in the back link (called the anchor text). For example, a link to Classy Delicates that said "lingerie" would be considered relevant, but one that said "cars" would be irrelevant.

Yahoo and MSN use the number of back links in their algorithms. Google places particular importance on back links. Google does not just consider the number of links, but also the "quality" of those links. Google assigns each page in its index a Page Rank (PR). Page Rank is a logarithmic number scale from 0-10 (with 10 the best). Google places more weight on back links that came from higher Page Rank sites.

Understanding the importance of back links, Steiner began a major link building campaign. First, he embarked on link exchanges with other lingerie sites. Second, he submitted Classy Delicates to a number of web directories. Directories are just categorized lists of websites. Third, Steiner purchased links. He spent $\$ 100$ per month for a package that allowed him to put links on up to 1,000 sites. These strategies, especially the links purchase, greatly improved Classy Delicates rankings on Yahoo. However, the site still did not rank well in Google.

In order to improve Classy Delicates' Google rankings, Steiner focused on higher quality links. He did this by posting comments on relevant Blogs with high Page Rank. He also submitted relevant articles to article syndication sites. Article syndication sites allow webmasters to place submitted articles on their site. So submitting to syndication sites actually provided back links from multiple sites. By focusing on higher quality back links, Classy Delicates began to rank well for "women's lingerie" on Google. 


\section{EXHIBIT 3: Use of Meta Tags in Organic Search Listings}

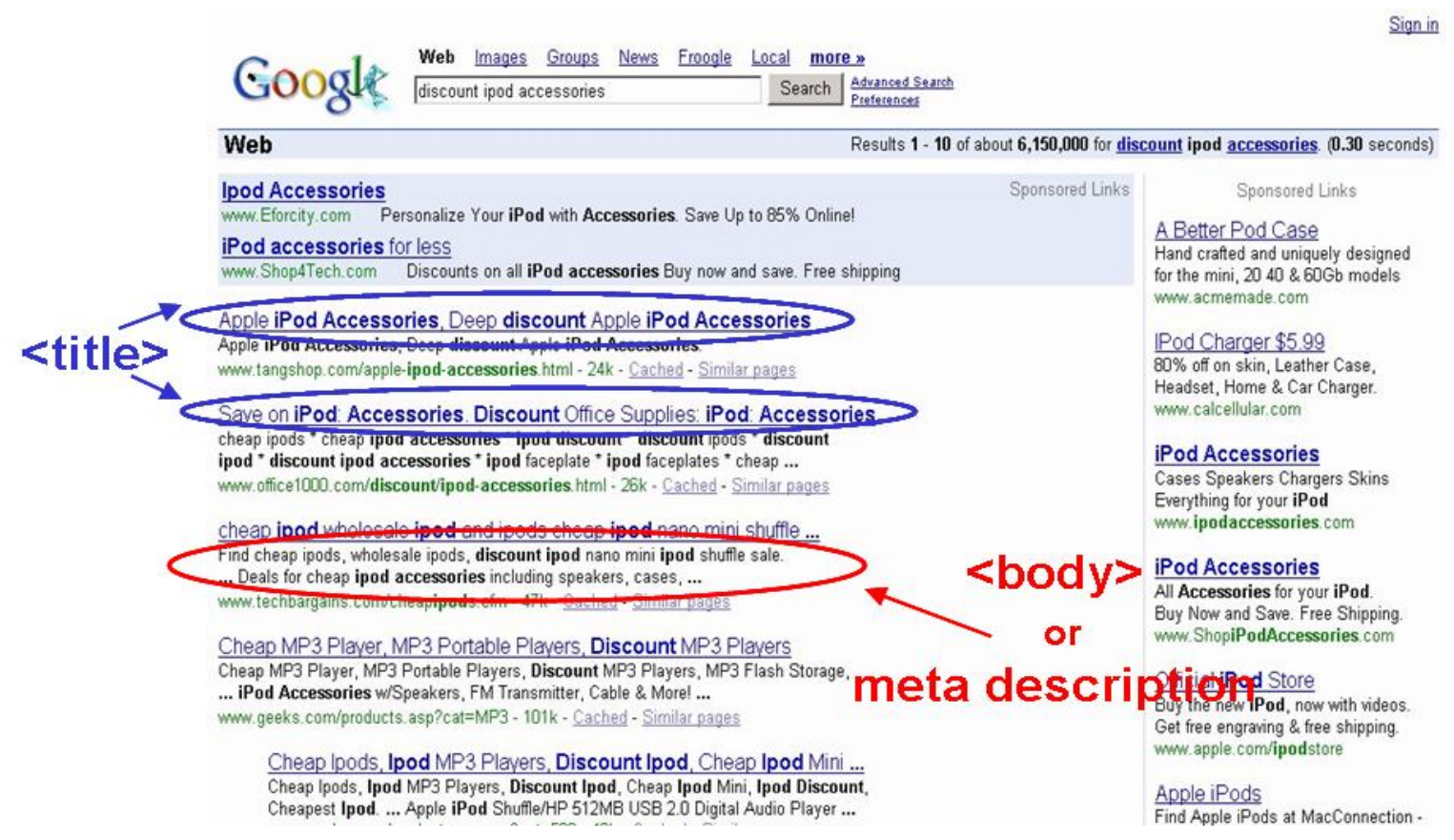

As Steiner had some expertise in SEO, he concentrated his efforts on it. By the beginning of 2006, Classy Delicates appeared in the top position for the term "women's lingerie" on Yahoo. In addition, the site usually appeared on the second page (positions 11-20) for the term "lingerie". The SEO strategy paid off because by June of 2007 , Classy Delicates was grossing upwards of $\$ 8,000$ per month.

The Classy Delicates website had monthly traffic of 35,000 to 40,000 visitors. However, Steiner was concerned at the low conversion rate (the number of site visitors who actually bought products) of less than one percent. In addition, Steiner's analytics (obtained from Google) indicated that a large number of visitors were starting, but not completing purchases. "I wonder why a visitor would take the trouble of looking at the product offerings, fill out most of the order form, and at this point change his/her mind about the purchase," remarked Steiner to his wife after looking at the analytics report in March 2007.

\section{THE LINGERIE INDUSTRY}

Lingerie was part of the apparel industry. Standard and Poor's reported U.S. apparel sales of $\$ 190.1$ billion in 2006, of which women's apparel was $\$ 102$ billion. U.S. per capita spending on apparel and footwear in 2006 was $\$ 1,226$. The U.S. apparel industry was large, mature, and highly fragmented. Imports dominated the industry and they exceeded domestic production by a significant margin.

Lingerie accounted for $\$ 9.6$ billion in revenues in 2005, an increase of 3.8 percent over 2004. Victoria's Secret, a division of the $\$ 10.67$ billion (in 2007) in revenues Limited Brands, and the privately owned Fredrick's of Hollywood were the two major players in the fragmented lingerie industry.

The Internet lingerie retailing industry features many operators operating out of the U.S. as well as from Canada, the U.K. and other European countries. While Victoria's Secret and Fredrick's of Hollywood typically competed at the middle to the upper end of the industry in terms of price and branding, at the lower end there were dozens of sites that sold merchandise from the same six to eight suppliers. These suppliers (such as Elegant Moments and DreamGirl) loosely enforced pricing policies that allow for keystone markups (100\% markup). While 
the profit margins were high, since everyone used the same suppliers it was difficult for a single vendor to differentiate.

Classy Delicates competed to some extent with the higher end lingerie retailers. However, the main competition was on the lower end, where many other retailers sold the same products as Classy Delicates. As suppliers attempted to enforce retail pricing, there was very little room to compete on pricing. Thus, most customers usually purchased on either the first site they found or the last site (after comparing prices). Therefore, it was vitally important for a lingerie website to show up as the one of the first few on a customer's web search.

Steiner reflected on his competition:

"When people think of lingerie, the names that usually come up are Victoria's Secret and Fredrick's of Hollywood. Victoria's Secret spends a lot of money on television advertising and has tremendous name recognition. To some extent, so is the case with Fredrick's. Either because of prices or the type of products sold in these two stores, I don't believe that my customers look at Victoria's Secret or Fredrick's before buying from Classy Delicates. My competitors are mid-to low price online lingerie retailers. The trouble is that my suppliers (Elegant Moments and DreamGirl) supply to a whole bunch of online vendors and we compete aggressively with each other. We can't really compete on pricing, so the key to success is to be either the first one to show up on the customer's search screen or at least be in the first ten or so. I need to attract customers to my website and increase the rate at which visiting customers complete the ordering process."

\section{BUSINESS PROCESSES}

Classy Delicates required minimal operational time for Andy and Julia Steiner. Periodically, Andy Steiner had to change the product images on the website when the vendors introduced new products. He paid a site hosting fee that was a set amount plus an amount that depended on traffic. These totaled anywhere between $\$ 300-400$ per month. He negotiated with Authorize.net for credit card processing for a fee of $2.25 \%$ of the transaction amount, plus transaction fees of about $\$ 0.25$ per transaction. He installed a toll free phone line for customer service that saved phone messages to be answered at a later time. The fee for this was $\$ 10$ per month.

Customers perused the website and placed orders. The ordering was complete when payment was made. A completed customer order automatically generated an email to the vendor. The vendor drop shipped the order directly to the customer and billed Classy Delicates on a monthly basis. Backorders posed a problem because they required follow up. Steiner spoke about the backorder issue:

"When a vendor was out of stock on a particular product, the customer's request was put on backorder. Now, officially, the vendor was required to inform me when the product was available to be shipped, but often the vendors did a poor job of it. After my customers complained to me about not hearing about backorders, I decided to take responsibility for it. Now, Classy Delicates keeps track of backorders via emails and telephone calls to vendors and we inform customers when to expect the order. We typically check with the vendors before we run specials on their items, but sometimes they are out of stock and hence, we get into the loop with the vendors and the customers."

As Andy and Julia Steiner got busy with their jobs and parenting their two young daughters, they decided to hire an assistant to manage the interaction with the vendors and the customers. Andy Steiner placed an advertisement on Craig's List for a "virtual" assistant - one who could be located anywhere but would work for Classy Delicates. Steiner hired an assistant who was paid $\$ 100$ per month for this responsibility. Exhibit 4 outlines the interaction between the vendors, Classy Delicates, and the customer. 


\section{EXHIBIT 4: Transaction Flow}

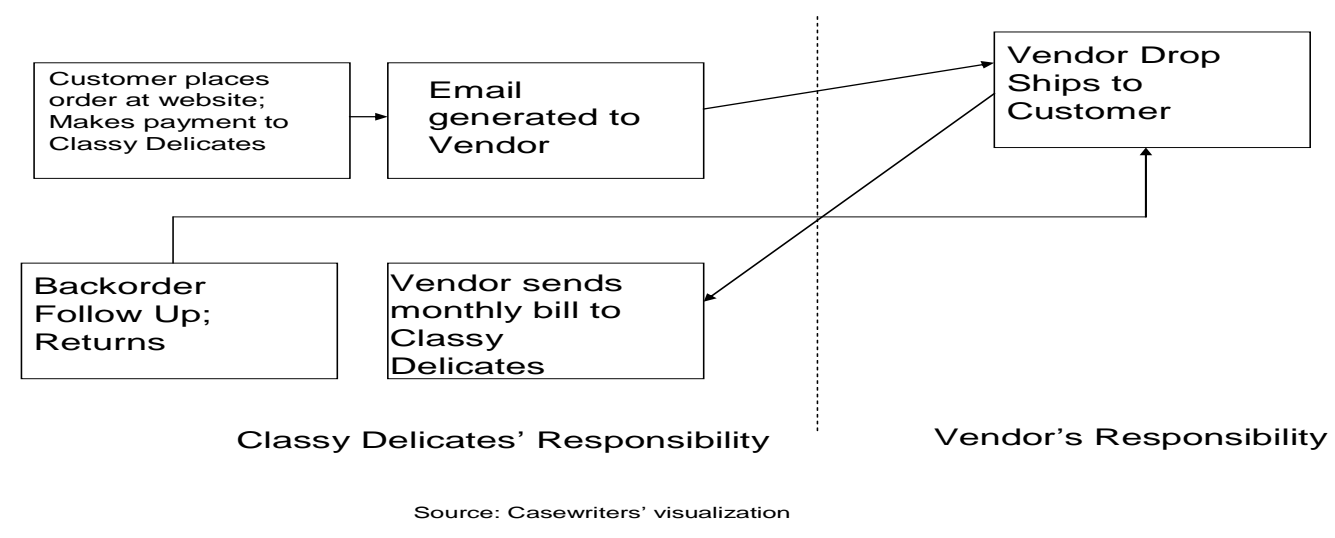

Steiner did not keep proper accounting books in the beginning and he gave the following rationale for it:

"I did not maintain proper financial records of Classy Delicates when I bought the business in August 2005. I had two reasons for this. The first was that we hardly had significant sales and I had a mental record of how much came in and the amount I paid for site hosting and other expenses. The bigger reason, though, was that I concentrated on helping improve site traffic by doing what I knew best - things such as SEO. Classy Delicates was not my full-time job; I had my academic job to attend to and Julia had just taken up a new job when we moved to New Jersey. These, along with the responsibility of raising two young daughters, took a lot of my time. I figured that I will get to the accounting part once I get more customers to visit my site." summary).

By June 2006, though, Steiner began keeping regular accounting records (see Exhibit 5 for a financial

Exhibit 5: Classy Delicates Financial Summary

\begin{tabular}{|l|c|c|c|c|}
\hline \multicolumn{1}{|c|}{ Month } & No. of Orders & $\begin{array}{c}\text { Gross Revenue } \\
\mathbf{( \$ )}\end{array}$ & $\begin{array}{c}\text { Cost of Goods Sold } \\
\mathbf{( \$ )}\end{array}$ & $\begin{array}{c}\text { Gross Profit } \\
\mathbf{( \$ )}\end{array}$ \\
\hline June 2006 & 77 & $4,166.05$ & $1,495.75$ & $1,874.39$ \\
\hline July 2006 & 72 & $4,316.97$ & $1,699.00$ & $2,141.26$ \\
\hline August 2006 & 53 & $2,985.26$ & $1,216.00$ & $1,450.23$ \\
\hline September 2006 & 46 & $2,699.65$ & $1,1018.65$ & $1,291.74$ \\
\hline October 2006 & 79 & $4,561.51$ & $1,598.35$ & $1,975.52$ \\
\hline November 2006 & 69 & $3,673.00$ & $1,321.20$ & $1,645.17$ \\
\hline December 2006 & 156 & $9,219.47$ & $3,285.95$ & $4,225.66$ \\
\hline January 2007 & 166 & $9,561.90$ & $3,512.10$ & $4,434.27$ \\
\hline February 2007 & 198 & $8,992.57$ & $4,199.20$ & $5,360.32$ \\
\hline March 2007 & 123 & $8,200.58$ & $3,096.10$ & $3,880.37$ \\
\hline April 2007 & 138 & $8,534.74$ & $3,097.85$ & $3,703.09$ \\
\hline May 2007 & 132 & $\mathbf{7 7 , 9 3 0 . 5 7}$ & $3,283.70$ & $3,813.88$ \\
\hline Total & $\mathbf{7 5 4}$ & $\mathbf{2 8 , 8 2 3 . 8 5}$ & $\mathbf{3 5 , 7 9 5 . 9 0}$ \\
\hline
\end{tabular}

Additional average monthly costs:

Site hosting - $\$ 300$ to 400

Source: Classy Delicates

Virtual assistant - $\$ 100$ 


\section{The Offer}

During the summer of 2007, Steiner decided to test the market by putting Classy Delicates for sale. He listed Classy Delicates for sales on BizBuySell.com in July 2007 that described his business and quoted a sales price of $\$ 120,000$. Steiner reflected on his move to offer the company for sale:

"I was not in any way compelled to sell Classy Delicates. My efforts at increasing site traffic was paying off and we were now making around \$2,500 a month in net profit. To be honest, running the business now did not take a lot of my time. My thought was to test the market by asking for an attractive price and to see if anybody bites. Considering that I paid $\$ 30,450$ for the business in 2005 , a price of $\$ 120,000$ means a sizeable profit. How did I choose my selling price of $\$ 120,000$ ? I looked at various websites that talked about price multiples and other factors for valuing a web-based business. One expert suggested 10 times annual profit. I was quite certain that it would not work in the case of Classy Delicates given the nature of my business, which was selling the products of vendors in a non-exclusive arrangement. I thought a multiple of four was high enough to satisfy my requirement, and I rounded it off to $\$ 120,000$. If I find a taker, perhaps I could invest the money in a new business."

Steiner received three offers prior to the one on August $3^{\text {rd }}$. The first offer was for $\$ 65,000$ while the second and third offers were in the $\$ 80,000$ range. Steiner immediately rejected the first offer which he angrily remarked to Julia was an "insulting and lowball offer." One of the second offers required Steiner to essentially finance the purchase. The potential buyer was willing to pay 25 percent down at the time of purchase and the rest over a two-year period. As Steiner was considering the two $\$ 80,000$ range offers, the fourth offer was made on August $3^{\text {rd }}$. This was from a buyer who already had two websites (both for non lingerie businesses) running on the same web host as that of Classy Delicates. His offer was $\$ 90,000$, cash down.

\section{The Decision}

Both Andy and Julia Steiner spent time going over these offers. Andy Steiner summarized their discussion and also gave his own thoughts on the offers:

"Perhaps \$120,000 was too high. Even then, when both Julia and I looked at the best offer of \$90,000, we were disappointed. Where was the '10 times earnings' that experts talked about? We probably can bargain with the fourth bidder knowing that he already has two sites on the same host and a third site would give him the scale necessary to increase his profits, but I don't believe we can go higher than $\$ 95,000$ or, at the most, \$100,000. I argued with Julia that with the way the site traffic is increasing, if we can increase the conversion rate even marginally, we can make the $\$ 100,000$ in about two years. But, as Julia pointed out, the price of $\$ 100,000$ means a sizeable return on our investment of $\$ 30,450$ two years ago. I have a profitable business, albeit one that does not have a defensible competitive advantage other than a favorable position on search engines. My product is not exclusive as others are selling the same thing. But, at a 100 percent margin, am I passing up a good opportunity to make a fair amount of money year after year by selling it now?

As Andy and Julia Steiner were debating the sale option, Julia reminded Andy that he had come up with an ambitious plan to make major changes to Classy Delicates. Andy's plan called from changing the site's shopping cart system to one who would charge $\$ 75$ a month instead of the $\$ 300$ that the current cart provider charged. Andy had received a number of quotes for switching to a new shopping cart system and redesigning the site. These quotes ranged from $\$ 5,000-8,000$. Andy's rationale for a new cart was not just the lower monthly fee but also the fact that the new cart would give him increased control to customize the site - control that was minimal in the current form. A major risk in shifting shopping cart systems was a possible loss in search engine rankings. Andy Steiner spoke about this option:

"I feel hampered by my current shopping cart system, particularly in the check-out process. Given that I lose a lot of customers at the check-out stage, perhaps a change can help me redesign and streamline the check-out process, as well as the overall design of the site itself. It will cost me money and, more importantly, the possibility of losing my current rankings on Google and Yahoo. That worries me!" 
Andy Steiner realized that he had a week to make up his mind whether to sell the business or continue running Classy Delicates. He wondered what he should do.

\section{AUTHOR INFORMATION}

Ram Subramanian is a Professor of Management at the School of Business, Montclair State University. He received his Ph.D. from the University of North Texas. Dr. Subramanian has published in a variety of journals including Journal of Management, Journal of Business Research, Management International Review, and Case Research Journal. He serves on the editorial board of The CASE Journal.

Ross A. Malaga is an Associate Professor of Management and Information Systems at the School of Business, Montclair State University. He received his Ph.D. from George Mason University. Dr. Malaga has published extensively in the area of electronic commerce in Communications of the ACM, Electronic Commerce Research, and the Journal of Organization Computing and Electronic Commerce. He serves on the editorial review boards of Information Resources Management Journal and the Journal of Electronic Commerce in Organizations.

\section{REFERENCES}

1. Burns, E. (2007). U.S. Search Engine Rankings, September 2007, Search Engine Watch, November 20, 2007. Retrieved November 25, 2007, from http://searchenginewatch.com/showPage.html?page=3627654

2. Google (2004). Google searches more sites more quickly, delivering the most relevant results. Retrieved July 17, 2006, from http://www.google.com/technology/index.html

3. Sen, R. (2005). Optimal Search Engine Marketing Strategy, International Journal of Electronic Commerce (10:1), Fall 2005, pp. 9-25. 


\section{NOTES}

